\title{
The role of complex social services for the children from families at risk
}

\author{
Vide Gudzinskiene and Rimvydas Augutavicius \\ Mykolas Romeris university, Lithuania
}

\begin{abstract}
The social assistance for social risk families in Lithuania is provided by child protection agencies, social welfare departments, family support and crisis centres, pedagogical-psychological services, care homes, various educational institutions and NGO's. One specific form of social support services for social risk families is called Children Day Care Centres (CDC), whose activities are based on a systematic set of measures designed to protect the social interests of children, to ensure social security and realize the basic needs. The aim of this research is to analyse the activities of CDC's in the context of helping to meet the needs of children at risk, who are also sometimes described in scientific literature as disadvantaged children. It is obvious that children growing within social risk families often do not have or have insufficient necessary skills-to communicate, to discover, to create. This significantly complicates the realization of needs of those children growing in families at risk or so called disadvantaged families. The social services in day care centres are organized for the best interests of such families. These institutions aim at giving the opportunities to meet the needs of children by creating the conditions to learn, create, spend their leisure time, and engage in a favourite activity.
\end{abstract}

Key words: social services, families at risk, children.

\section{Introduction}

At the end of 2017 over 10000 families were found to be at risk in Lithuania, and more than 21000 children growing up in these families. One can imagine that it can be around 40000 children and adults that are distinguished as people at risk, and this is the total population of the $7^{\text {th }}$ biggest town in Lithuania - Marijampole. Such high number of families at risk, regardless of the fact that the number has been decreasing slightly over the last few years (correlating with the decreasing population of the Country), has to be targeted by the social welfare services in order to minimize the negative impact on the economic and social context of the country. Numerous services provided for adults at risk proved to be of very little effectiveness and it is often facing difficulties due to the low motivation of such people to receive services, while the children are easier to reach and affect by both governmental and nongovernmental organizations performing in the area of social welfare.

One particular type of services or method to provide services for the group of children, in Lithuania is called Day care centre for children, which is designed to contain different interventions provided in one place for the number of children. This kind of complex service is attractive due to its flexibility, informal design and being introduced in the natural living environment of families at risk making it accessible and helpful in organizing after school care. On the one hand, this is to be considered as a support provided for parents (after school 
care). On the other hand, it can also be considered as an effective primary and secondary prevention as well as intermediate level post prevention measure that aims to break the chains of social inheritance of risky behaviour and lifestyle practices within the family. It is also important source of influence in respect of social learning and modelling of behaviour of children at risk.

In general complex services for families is the definition for a services provided for a family that cover complex needs of all family members and is distinguished by well managed and organized structure of these services. These services aim to address the issues of the family itself and sole family members. They are also coordinated by one person who is responsible for identifying the issues, assessing the needs and making decision for the type of the service needed.

This subject of research and study is popular among the Lithuanian and foreign authors. Analysing the experience of foreign countries authors [1] highly emphasise the possibilities of prevention of domestic violence. Analysing the neglect of children from families at risk [2] the authors have focused on the pre-school age children in rural areas. According to the findings of the concrete research [3] the educators should take the role of social workers as well - building the close relationships with students and communicate openly, encourage them to confide in harrowing matters. Other authors [4] analysed the various problems arising within the professional social work with children and tried to identify the role of social workers in respect of the concrete situation. The social context of social risk families [5] was greatly analysed in the frame of the newly formed factors affecting the expression of social tensions. On the other hand, the psychological, social, and learning difficulties of the children from the families where parents abused alcohol [6] were also taken into account. The study focused on the psychosocial crises of mothers and their possible negative effects, such as alcohol, drugs abuse and the impact of these characteristics on children [7], while other research [8] focused on the social skills and professional competencies of the staff members of day care centres for children.

The study of complex services provided in children day care centres in Lithuania was directed towards the prevention of social problems of families and children at risk. It had been very fragmented, and the capacity of the complex services in meeting the needs of children in the centre generally has not been studied. The study attempts to view the needs of children at risk and capacities of the day care centres providing complex services for children and families to meet them in greater focus. The subject was analysed in the following aspects: the capacities to meet the needs of children at risk in day care centres through the number of different activities and types of services; and the benefits or complex services brought to the disadvantaged families and children.

\section{Aim and methods}

The aim of the research is to analyse the activities and types of services provided within the day care centres in the context of helping to meet the needs of disadvantaged children from families at risk.

Objectives: 1. To highlight the needs of children of social risk families and the specifics of the services provided in the children day care centres. 2. To discuss the capacity utilization of the children day care centres to meet the needs of children at risk. Survey sample the employees and volunteers working in the children day care centres (CDC) in the most disadvantaged areas of the country. 106 employees and volunteers involved in children day care centres participated in the study. The minimum period of 1.5 years of involvement in $\mathrm{CDC}$ was the main criteria for choosing respondents. 
Study organization - the study was conducted using IT. A questionnaire was posted on the site www.apklausa.1t. Link to the e-survey was e-mailed to the heads of the CDC, at the same time asking for the permission and mediation to interview their staff. Respondents answered questions anonymously. The total number of 106 responses was achieved. The study was carried out in January-February 2016.

Study data collection methods - the survey with e-questionnaire was used in order to study the possibilities provided by CDC to meet the needs of children of social risk families. The question of the questionnaire were constructed using a nominal and ordinal scales, all questions were closed-ended.

Data analysis methods-data was processed using Microsoft Excel for Windows and SPSS17.0 (Statistical Package for Social Science) software. Relations were assessed using Spearman correlation coefficients. Statistical error probability critical threshold indicates the permissible size of the statistical error in the decision. $P<0.05$ statistical margin of error was used in this study. Thus, the statistical solutions that do not meet the conditions of $p<0.05$, will be considered as invalid in this study.

Ethics of study. The study met the requirements for ethical research. Respondents were not asked to answer personal questions, they all participated in the study voluntarily, answered questions anonymously, were introduced to the content and purpose of usage of the data obtained during the survey.

\section{The needs of children of social risk families}

Authors claim that the families at social risk are distinguished by several characteristics [9], such as - there is more than one specific internal or external social issue or a problem, a crisis situation in the family that makes the families at risk to be one of the most disadvantaged target groups in the society, families at risk, due to the nature and complexity of the social issues faced, are not capable to manage their own lives, as well as to provide appropriate care for the children.

Various criteria are used to define the family at social risk in both legal documents and academic literature. These families usually misuse alcohol and other substances, often are characterised by abusive nature of behavioural patterns; abuse of the financial support (benefits) provided by the State to support the family; are not capable to meet the even the basic needs of their children; are lacking social and parenting skills. In general, the definition of such family would describe the current situation in the family: facing complex of several social issues that cause concrete serious risk to the wellbeing of the children and their adequate development as well as the safety. It also requires the external intervention as the families at risk are not willing or do not have capacities to help themselves.

The two types of needs inherent for humans have also been emphasised [6]: 1) biological needs - these are defined as an absolute dependence on the physical conditions essential to the existence, as the failure to meet them would cause death (food and water); 2) social needs these are defined as the dependence on the relationships and communication between people. The failure to meet these kinds of needs will not be fatal; however, these needs motivate and encourage people to communicate and collaborate with other people. The need can be described as a state of the individual [10]. This may be a lack of something, or the requirement for something when the internal and external functioning conditions do not match.

According to Maslow's theory of needs hierarchy a person reaches the fullness of life when meeting the highest needs in the hierarchy - actualizing and realizing themselves. This theory emphasizes that the emergence of higher needs is based on the satisfaction of lower ones. The new basic needs emerge in every stage of psychosocial development of child. 
Lacking the possibilities to meet these needs, the child faces difficulties to overcome the crisis specific to every stage, which obviously negatively affects the dynamics of development and the physical health. Based on the theory of Ericson E, many authors believe that the 6-11-year life stage is characterized by excellence (diligence), or worthlessness. It is very important to encourage the child to perform independently or complete the task on his own in this stage. When a child is not encouraged or when attention is not paid to his efforts to carry out the work - the feelings of worthlessness are developing.

One of the most obvious problematic cases when the needs of the child are not met in the family is when the family is considered as the family at risk. In order to provide the support for the children to meet their needs various forms of political and social action are employed. Furthermore, the need is the element that is needed for the person or social system to successfully function in specific conditions [11]. The need is not something one is wishing to gain or have - it means a lack which barriers a person or system to develop and grow.

The laws in Lithuania [12] define social services as a form of non-monetary assistance to people when other guarantors of the social security system are not effective. Although this definition is quite general and is suitable for most services, a more detailed regulation of social services is dependent on the same social work content and organization within different types of social service agencies [13]. Moreover, the authors argue that the definition of social services can be explored further - these are such services, which aim to improve the quality of life and provide better living conditions for people who partly or in whole are unable to take care of themselves. Based on this definition, social services, as well as all other services can be bought or sold in the market. Social services for socially disadvantaged families or families at risk are provided in order to develop the initiatives and motivation of grown up members of the families to create a safe, healthy and harmonious environment for children. Social services focus on maintaining close family relationships with the society, and on ensuring the education, coaching and development of the children [14-17].

In addition to the biological needs, the 6-11 years old children have characteristic social needs: learning and cognition, while the children from the age of 12 - integration of social roles and the identity search. In order to meet these needs the active participation of children in the social life is required - within the family, school, friends circle.

12-19 years age group is considered as teenagers [6]. Obviously, it is stressed that identity or the uncertainty in respect to social roles is characteristic to this stage. At this period of age, psychic-physical changes are causing many teenagers suffering inexperienced feelings, so it is important that the teenagers purposefully integrate their social roles that would help to achieve the self-awareness.

It is obvious that children growing in social risk families often do not have or have insufficient necessary skills-to communicate, to discover, to create. This significantly complicates the realization of needs of those children growing in disadvantaged families. The social services in day care centres are organized for the best interests of such children The activities organized in day care centres come under several types: sapid occupation and free time activities; physical and social environment for learning, communication and discovery.

\section{The functions of CDC's}

The social support system that is currently functioning in Lithuania aims at providing and ensuring the social and financial assistance to the disadvantaged families and the children. The services are designed to promote the motivation and activity of families affected by social risk in the field of overcoming children education problems [18].

CDC aim is to provide non-institutional childcare, the organization of extra curriculum activities in order to meet the needs of children that are not met within the family for various 
reasons. On the other hand, CDCs provide support for parents in developing their parenting skills. Generally, CDCs have the following main objectives [18]: 1) help to solve the issues and problems that children growing in social risk families are facing - via education, informal learning, activities and social work with parents at risk; 2) to ensure the adequate conditions for the socialization of children; prevention of children involvement in criminal activities, coordination of social services provision for social risk families.

In respect to the above objectives the essential tasks of CDC are distinguished: 1) The provision of various social services (education, psychological and social) in order to develop appropriate social skills (communication, cooperation, self-employment) that are essential for the better integration of social risk families and children in society; 2) Active cooperation and work with the family in order to ensure appropriate conditions for the growth of the children; 3) The organization of sapid occupation and free time activities for children growing in disadvantaged families, aiming at prevention of the children of using the substances and getting involved in criminal activities; 4) Strengthening the moral attitudes and values of the children, hoping that they will become functional members of the society; 5) Contributing to any social problem-solving, prevention initiatives and ensuring the security and safety of the society [19].

It is also important to pay attention to the fact that not all the CDC's in the country are creating the conditions for the realization of the children's needs and this is mostly predetermined by the lack of resources (poor working space, lack of finances or educational and work materials). This fact requires further studies of the opportunities offered in the CDC's to meet the needs of the children from families at risk. Although the first children day care centre in Lithuania was founded in 1996 in Kaunas, we still lack the studies of the capacities and activities of CDC's as they are mainly analysed in the management approach technical cooperation possibilities, coordination and administration of the centres are the main fields of studies. The experience of grownups are mainly discussed in these studies the competences of the staff, the work content and other things, however the activities of the CDC's are mainly focusing on the children and their experiences are very little studied.

\section{The empirical data analysis}

Characteristics of the respondents The 106 respondents were involved in this study. The majority of the respondents were females (91.5 percent). The distribution of respondents according to age was rather uneven - the biggest percentage (41.5 percent) was in $41-50$ years old group while the least $(1.9$ percent $)-$ in $<20$ years age group. The majority of the respondents (69.8 percent) have had a university degree. The social workers compounded one third of all respondents.

It has been discussed earlier that children from the families at risk often are not provided with the appropriate possibilities to learn and develop both socially and psychologically in their natural living environment. In order that their socialization process is not disrupted and the children from the disadvantaged families are successfully integrated into the society, there is a need for the urgent and successful intervention. We considered that CDCs, providing complex services, are giving such opportunity to the children. On the other hand, the capacities of the CDC have never been discussed before and there was a need to identify their capacity utilization. In general, the research has helped to focus on the CDC's staff and volunteers' opinion on the needs of children in need and the level of realization of these needs.

The opinion of the CDC staff and volunteers in respect to educational needs of the children at risk reveals that the most important educational needs of children are selfexpression education and training activities (80.2 percent), learning to look for information 
in the CDC library (69.8 percent), as well as artistic and creative activities (67 percent). The respondents were also asked to answer how much time is dedicated to educational activities in CDC's. More than half of the respondents (58.5 percent) indicated that 1 to 2 hours are dedicated to education, preparation of homework every day, almost one-third (32.1 percent) indicated 2-3 hours, a small number (9.4 percent) claimed they only spend less than 1 hour a day. Most of the respondents (82.1 percent) claimed that the educational needs of the children from social risk families, who attend CDC's, are fully met.

The study also sought to find out frequency of the educational activities in CDC. It has been estimated that in most of CDC's the educational activities were organized 3-4 times a week or even more often (60.4 percent), 1-2 times a week (34 percent), 1-2 times a week once in two weeks (5.7 percent).

Using the Spearmen correlation coefficient the CDC staff and volunteers' opinion was determined on the reasons why children from families at risk, who had difficulties at school, attended CDC. The respondents agreed that it was because of the educational activities, organized 3-4 times a week or more. The key statistical link $(r=0.434, p=0.04)$ between these symptoms has been identified.

Those children, who do not have possibilities for proper rest and conditions to do homework, can have a variety of emotional and behavioural disorders at school (6). Thus, it is important that the children from social risk families could realize all their educational needs in other environments.

The study also tried to disclose the CDC staff and volunteers' opinion on essential social needs in respect of social skills of the children from families at risk. The respondents accepted all of the proposed claims, however, focused on the development of communication skills most of all (92.5 percent). The communication is the basis for co-operation, every person should be able to communicate in order to share their experiences with other members of society, able to work together to achieve a common goal. Obviously, it is possible to realize the communication needs or to gain recognition, constructively discuss only while being in a group [14].

Particularly significant in the sense of children socialization is respondents' preference to the encouragement of comprehension, tolerance towards the smaller children (89.6 percent). More than a half of school age children in the country suffer bullying in schools, as well as the same number of them are bullying other children [20]. Moreover, approximately one-fifth of schoolchildren are experiencing physical abuse at schools. Having these numbers in mind it is very important to encourage the development of tolerance and promote the discussions about morality and values while working with disadvantaged children growing in families at risk. It can also be proposed that the children attending CDC would develop essential social skills, as $88.7 \%$ of respondents emphasized the development of child's responsibility. The personality taking the responsibility for their actions and interests is valued not only by the people, who are directly dealing with them, but also by the society as a whole.

The child growing in social risk family usually lacks social skills [6]. One of the objectives of CDC's is to enable the children at risk learning how to overcome the difficulties they face in socialization process. Surely, it is obvious that only a socially mobile person can successfully integrate into society and be useful to themselves and others. Thus, the study aimed to find out what is the focus level on the development of children's social skills in CDC. For this reason, we asked the respondents how much time per day CDC's focus on the development of social skills. It was found out that the most of CDCs (77.4\%) spend $>3$ hours per day developing social skills of disadvantaged children. $19.8 \%$ spent 2 to 3 hours a day, while $2.8 \%$ - less than one hour. It could be claimed the CDCs pay enough attention to the development of social skills of children in need, which allows the assumption that these children are given the possibilities to meet their social skills gaining needs. 
It was found out that one of the reasons why children from social risk families attend $\mathrm{CDC}$ is the fact that they are brought to the $\mathrm{CDC}$ by social pedagogues working in schools. It is related to the fact that in order to meet the social skills development needs in CDC children communication skills development and children understanding, tolerance, tolerance promotion are organized.

The application of Spearmen correlation coefficient established a strong statistical relationship between the variables $(r=0.758, p=0.001)$ in the first case - the child from social risk family brought to CDC by social pedagogue has been characterized by the lack of communication skills. In the second case, the weak link between the variables $(r=$ $0.382, p=0.01$ ) has been identified - such child also lacks the understanding, patience and tolerance to others. Most of the respondents $(67 \%)$ claimed that the social needs of children in respect to social skills were fully realized. Almost one third (30.2\%) of respondents indicated that these needs are met at the medium level, and only $2.8 \%$ considered that the social needs related to social skills were not met and this could be identified as a problematic aspect in the CDC functioning.

The way the person is spending his free time has a great influence on the purposeful development of the personality [21]. Purposefully planned leisure not only helps a person to discover the favourite areas, develop the creativity, communication skills, but also prevents the individual from aimless wasting of time. This is especially important subject of study in respect to children at risk, as the aimless free time can lead them to criminal activity, and inappropriate social contacts. Social risk families are often not particularly interested in what their children do after school, while the child at risk has no abilities to choose and organize the appropriate free time himself.

We wanted to identify the activities provided by CDCs in order to ensure sapid occupation and free time for children at risk. The target group children are supposed to have much free time, and it is important that they have the opportunity not only to participate CDC community life, but to spend some time in other environments (summer camps, excursions), and thus to expand their horizons and gain more experience. CDCs initiated the involvement of children in the events, competitions, public actions organized by school or municipality (67 percent). It is important to note that significantly less often children go to excursions, trips to the countryside, museums and exhibitions $(42.5 \%)$, as well as to summer camps (17\%). Trips to other environments expand personal horizons, help to understand the differences between social decisions, give the possibility to meet new people, get into new situations. Most of disadvantaged families lack sufficient financial resources or simply an interest in organizing trips for children themselves, thus it is important that these activities were organized by CDC. The respondents were asked how often CDC initiated the organization of free time and leisure activities (out of $\mathrm{CDC}$ ) for children at risk. It was interesting to find out that most of these activities have been organized in CDC's only once a month or even less often $(89.6 \%)$. Only a small number $(10.4 \%)$ of respondents indicated that such activities are organized 1-2 times in three weeks. Obviously, this could be influenced by the limited CDC financial resources. The children from social risk families often lack social activity as well. Therefore it is really important that disadvantaged children living in families at risk had the opportunity to spend their leisure time purposefully - to see new things as well as learn something, to take part in certain activities and try themselves in new activities, looking for their identity at the same time [22]. According to the opinion of the respondents of the study, the social needs related to the meaningful free time of children in families at risk were poorly met. Almost one-third (29.2\%) of the respondents claimed that they believed that these needs were met at the medium level. The data indicates limited CDC opportunities to meet the social needs related to the meaningful free time of children at risk. There obviously is the need to identify the reasons that limit the realization of these needs. 
- Capable of meeting the needs fully

- Intermediate level of capability to meet the needs

Insufficient capability to meet the needs

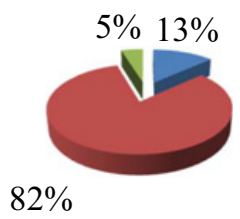

Fig. 1. The opinion of the volunteers and employees of the $\mathrm{CDC}$ on the capacity to meet the needs of healthy lifestyle, $(\%), n=106$.

We have also focused on the association between the respondents' opinion that the difficulties they are facing in their work affect realization of the need of children at risk and the opinion that children's needs in respect of meaningful leisure are poorly realized. Spearmen correlation between these traits shows essential statistical correlation $(r=0.432, p=0.04)$. Difficulties appear in work with disadvantaged children in families due to the satisfaction levels on children leisure time activities. The application of Spearmen correlation coefficient established a strong statistical relationship between the variables $(r=0.432 ; p=0.04)$. In this case - difficulties in working with disadvantaged children affect the realization of social needs associated with sapid free time and leisure.

The study aimed to find out the social needs of children attending CDC's in relation to the healthy lifestyle. The majority of the respondents emphasized the education of self-care and personal hygiene. It should be noted that the least of respondents emphasized children's sexual education $(30.02 \%)$ and children's interest in the promotion of healthy diet (46.2\%). Keeping these findings in mind it is obvious that the situation is not consoling, as parents of the children at risk often avoid speaking about issues of sexual education with their children, are not interested to do this or simply are not able to disclosing the topic. On the other hand, parents of social risk families are not interested in developing the healthy lifestyle skills. Due to the lack of economic resources or appropriate knowledge, the diet is not balanced, the children lack physical activities, are keen on passive way of their leisure.

It is particularly important to encourage children to choose the healthy lifestyle in the childhood - physical activities, proper diet, as certain knowledge of the child will help to prevent a number of health problems in the future and also to maintain a positive attitude towards learning and, in general, to achieve their goals [23]. Some authors also highlight the exceptional importance of the healthy menu in CDCs in formation of healthy lifestyle [24].

Thus, respondents were asked how much time is spent daily in CDC to develop the skills of healthy lifestyle and similar needs. The answers showed that majority (78.3\%) of the CDCs spent 1-2 hours per day for activities devoted to promotion of healthy lifestyle. Of the respondents 17 percent claimed that they spent only $<1$ hour per day on such activities in CDC, another 4.7 percent of the respondents claimed their CDCs offer 2-3 hours for healthy lifestyle promotion activities daily. According to the opinion of $82.1 \%$ of the respondents (Fig. 1) the social needs of target group in respect to healthy lifestyle development were realized at medium level. The opinion that these needs are met fully was recognized by only $13.2 \%$ of all respondents.

We wanted to find out whether the participants' opinion that social needs for healthy lifestyle of children at risk are realized at medium level is associated with the opinion that the $\mathrm{CDC}$ volunteers and staff are currently experiencing lack of competences related to work with 
social risk families. Application of Spearmen correlation coefficient between these variables identified weak statistical correlation $(r=0.38, p=0.01)$. On the other hand, lack of the competences can also affect certain level of the realization of social needs in CDC.

Thus, summarizing the data of the study we can note that the CDC staff and volunteers emphasize self-realization development activities as the key educational needs of children from social risk families. The importance of the educational needs can be identified from the fact that educational activities in the CDCs are organized more often than others. The social skills development activities are also organized rather often while the sapid free time and leisure activities are the least popular in CDC.

In the frame of social skills development, the respondents of the study most often emphasize the promotion of understanding and tolerance among the children at risk. As to leisure time needs - the opportunities to participate in the events, contest and competitions organized by local schools and municipalities. Concerning healthy lifestyle education, the respondents emphasize the development of self-care and personal hygiene skills. Summarizing it is important to notice that the best realized needs of the children from social risk families are in the areas of education and social skills development. Meanwhile the healthy lifestyle development needs are realized at medium level and the leisure and sapid free time needs are poorly met. In general, it is essential to promote and develop the opportunities to meet the healthy lifestyle and leisure needs of children at risk. This is also very important because of the fact that the CDC services are also offered for the adolescents (11-13 years old) who are experiencing one of the most problematic development stage and usually are particularly sensitive.

\section{Conclusions}

1. According to the findings of the various scientific research and legal documents, the social risk family is described as the family where the parents due to the patterns of maladaptive behaviour, difficult economic circumstances and other reasons are not capable of functioning adequately in the society. They may also experience the negative effects of these characteristics that put them at risk position. The complex negative aspects of their personal abilities, characteristics, as well as external features of the environment and social context are correlating with the belonging to the risk group. Obviously, the needs of the children living in these families are often neglected because of the lack of parental skills, appropriate values and other social issues. The socialization of the children is often impaired.

2. One of the possibilities and methods that is directed towards meeting the needs of those children from disadvantaged families is provision of complex services and after school activities in children day care centres. These agencies can be considered as the national strategy employed in order to reach the children and their families in their natural environment as the part of support offered for the disadvantaged families. These centres provide the children with the opportunities to meet their needs by creating a positive environment for informal education, creativeness, and for spending their leisure time being engaged in various activities. These services help gaining the communication skills, enable children to satisfy their core needs and develop self-confidence.

3. The empirical study revealed that the CDCs organizing their activities and providing complex services for the children in the most disadvantaged communities around the country, would usually employ such strategies as providing both formal and informal educational; counselling, information and awareness raising. In general, CDCs are more likely to have greater capacity providing the possibilities to meet 
the needs of children from families at risk in the field of development of social skills and education, while the promotion of healthy living lifestyle skills is not fully developed.

4. The study of the opinion of CDCs social workers and volunteers on the capacity utilization of these centres revealed that the educational activities in CDCs are organized more often than others, as they are responding to the fact that the children from social risk families are facing learning difficulties more often than the children from general population. The activities meant for developing self-expression are also considered to be one of the most important, as this is the way to stimulate and build self-confidence and learning social communication aspects. The majority of CDCs organized activities that were stressing the promotion of understanding, tolerance and respect.

5. The reason for poor realization of the leisure and sapid occupation needs of children at risk could be explained by lack of the professional competences volunteers and employees of CDCs can use in their practice. This can also be responsible for the insufficient level of the realization of healthy lifestyle needs.

\section{References}

[1] B. Palavinskienè, Jurisprudencija. Mokslo darbai 20(12) (2001)

[2] E.A. Hanushek, M.E. Raymond. J. Policy Anal. Manage. 24(2), 297-327 (2005)

[3] B. Kairienè, Socialinis darbas. 5(1), 89-95 (2006)

[4] L. Dromantienè, R. Šalaševičiūtè. Socialinis darbas 5(1), 79-88 (2006)

[5] G. Kondrotaité, Sociologija. Filosofija. 4, 55-60 (2006)

[6] V. Gudžinskienè, R. Gedminiené, Socialinis ugdymas 27(16), 19-31 (2011)

[7] T. Angarne-Lindberg, M .Wadsby, Soc Psychiatry 58(1), 16-25 (2012)

[8] V. Gudžinskiené, A. Railienè, Acta Paedagogica Vilnensia 29, 72-91 (2012)

[9] J. Vyšniauskytė-Rimkienė and others, Socialinis darbas. Patirtis ir metodai 12(2), 121-140 (2013)

[10] V. Atkočiūnienè, S. Navasaitienè, A. Aleksandravičius, Management theory and studies for rural business and infrastructure development 3(32), 5-14 (2012)

[11] J. Leonavičius. Sociologijos žodynas (1993)

[12] Lietuvos Respublikos socialiniu paslaugu istatymas, 1996 m. spalio 9 d. Nr. I-1579, Vilnius. Valstybės žinios (1996). Nr. 104-2367

[13] A. Guogis, D. Gudelis, Viešoji politika ir administravimas 12, 77-85 (2005)

[14] Paslaugos socialinès rizikos šeimoms. Available at: http://www.panspc.lt/ 2-3-.htm

[15] Socialinès rizikos šeimu, auginančiu vaikus, îrašymo i apskaita, išbraukimo iš apskaitos tvarka. Available at: http://www.joniskis.lt/Veiklos-sritys/ Vaiko-teisiu-apsauga/Socialines-rizikos-seimu-auginanciu-vaikusirasymo-i-apskaita-isbraukimo-is-apskaitos-tvarka

[16] Socialinès rizikos šeima. Available at: http://www.vaikoteises.lt/lt/vaiko_ teisiu_apsauga/socialines_rizikos_seima;

[17] Socialinès rizikos šeimos metu pabaigoje. Požymiai: administracinè teritorija. Available at: http://db1.stat.gov.lt/statbank/selectvarval/saveselec tions . asp?MainTable $=$ M3160902\&PLanguage $=0 \&$ TableStyle $=\&$ Buttons $=\& P X S$ $\mathrm{Id}=6558 \& \mathrm{IQY}=\& \mathrm{TC}=\& \mathrm{ST}=\mathrm{ST} \& \mathrm{rvar} 0=\& \operatorname{var} 1=\& \operatorname{var} 2=\& r \operatorname{var} 3=\& r \operatorname{var} 4=\& \operatorname{var} 5=\&$ $r \operatorname{var} 6=\& r \operatorname{var} 7=\& r \operatorname{var} 8=\& r \operatorname{var} 9=\& r \operatorname{var} 10=\& r \operatorname{var} 11=\& r \operatorname{var} 12=\& r \operatorname{var} 13=\& r v a r$ $14=$ 
[18] E. Masiliauskienè, V. Griškutè. Mokytojụ ugdymas 14(1), 138-155 (2010)

[19] Vaikụ dienos centrai (2008). Available at: http://www.gelbvaik.1t/gelbvaik/ node/37

[20] Visuomeninė organizacija "Gelbèkit vaikus" (2013). Veiklos ataskaitos Available at: http://gelbvaik.1t/ka-mes-darome/veiklos-ataskaitos/

[21] F.C. Yuen, A. Pedlar, R.C. Mannell, J. Leisure Res. 4, 494-518 (2005)

[22] D Antinienè, R. Lekavičienè, Psichologija 45, 89-102 (2012)

[23] N. Frishman, M.C. Shelley, Social thought Res. 32, 47-69 (2013)

[24] L. Mann, D. Power, V. MacLellan, Canadian children 2, 34-40 (2013) 